\title{
The Politics of Reflexivity in Music Teachers' Intercultural Dialogue
}

\author{
Vilma Timonen, Marja-Leena Juntunen, and Heidi Westerlund
}

\begin{abstract}
In this chapter, we explore the politics of music teacher reflexivity that emerged in a transnational collaboration between two institutions, the Nepal Music Center (NMC) and the Sibelius Academy, University of the Arts Helsinki when co-developing intercultural music teacher education. We examine in particular the reflexivity in this intercultural dialogue and how the collaboration became a complex field of issues of power related to social positions and epistemologies. Such reflexivity may act as an invitation to discomfort but at the same time as an invitation to deep professional learning. The empirical material was generated in the flow of activities within teachers' pedagogical studies organized by the Sibelius Academy for the NMC teachers in Nepal. The authors' experiences and the omnipresent colonial setting were taken as a backdrop of the overall interpretation and discussion. We argue that in an intercultural dialogue, negotiating one's premises, stance, and the ethical relations with the Other requires reflection on one's existential groundings. However, professional learning in intercultural dialogue is prone to persistent paradoxes that cannot be swiped away, or even solved. The politics of reflexivity thus keeps the questions open, with no final answers or ultimate solutions.
\end{abstract}

Keywords Reflexivity · Politics of reflexivity · Deep professional learning · Intercultural dialogue $\cdot$ Music teacher education

\footnotetext{
An earlier draft version of this chapter was published as part of Vilma Timonen's doctoral dissertation: Timonen, Vilma (2020). Co-constructing globalizing music education through an intercultural professional learning community - A critical participatory action research in Nepal. University of the Arts, Helsinki. Studia Musica 83. ISBN 978-952-329-171-3.
}

V. Timonen $(\varangle) \cdot$ M.-L. Juntunen $\cdot$ H. Westerlund Sibelius Academy, University of the Arts Helsinki, Helsinki, Finland e-mail: vilma.timonen@uniarts.fi; marja-leena.juntunen@uniarts.fi; heidi.westerlund@uniarts.fi

A. A. Kallio et al. (eds.), The Politics of Diversity in Music Education, Landscapes: the Arts, Aesthetics, and Education 29, https://doi.org/10.1007/978-3-030-65617-1_4 


\section{Introduction}

Reflective practice and the reflective practitioner are established concepts in the international literature on teacher education and teachers' professional development (e.g., Cochran-Smith and Lytle 1999). In music education, a reflective practitioner typically refers to the socioculturally formed thinking that is part of a cognitive apprenticeship, where one learns to think in action and reflect critically while focusing one's attention and awareness on the details of music making, listening, or other musical activities (Elliott 1995). Moreover, the concept of "reflection" has often been reserved for thinking processes that are "linked to learning 'how' rather than learning 'about' or 'what" (Leitch and Day 2000, p. 180). In other words, the starting point is that reflection is about the 'hows' of acting according to the known and valued practices, instead of questioning and changing any elements of the practice or tradition. As described in Schön's (1983) work, many of the reflective practitioner's tacit processes of thinking, which take place in tandem with doing, remain unconscious. Through the two forms of reflection - reflection in action and reflection on action - that according to Schön form the "epistemology of practice" (p. 49), the practitioner can become aware of the success and relevance of his actions and accordingly change "the situation from what it is to something he likes better"(p. 147). Reflection is therefore often limited to "an in-depth consideration of events or situations outside of oneself” (Bolton 2010, p. 13). Reflexivity, however, relates more to thinking about the mind itself and refers to "finding strategies to question our own attitudes, thought processes, values, assumptions, prejudices and habitual actions, to strive to understand our complex roles in relation to others" (Bolton 2010, p. 13). According to Bolton (2010):

[t]o be reflexive is to examine, for example, how we - seemingly unwittingly - are involved in creating social or professional structures counter to our own values (destructive of diversity, and institutionalizing power imbalance for example). It is becoming aware of the limits of our knowledge, of how our own behavior plays into organizational practices and why such practices might marginalize groups or exclude individuals. (p. 13-14)

Intercultural dialogue has been said to provoke such reflexivity (Westerlund et al. 2015; Mateiro and Westvall 2016). This kind of reflexivity, which requires becoming aware of power structures, stepping into uncertainty, and engaging in complex dialogue, can emerge "between the diverse cultural logics that attend different cultural territories" (Biddle and Knights 2007, pp. 5-6). In such intercultural dialogue, there is a new need to see culture as constantly undergoing "co-constructions, negotiations, questionings (...) manipulations and instabilities" (Dervin and Machart 2015, p. 3). This kind of reflexivity is more related to one's own existential groundings and is expected to provide "support for cross-cultural dialogue" (Nasar et al. 2016, p. 5), through which professional identities and epistemologies can be seen as ongoing change processes. Moreover, such dialogue requires "a commitment to discomfort, a commitment to questioning oneself and one's identity, a commitment to engagement with difficult truths and alternative histories, a commitment to developing ethical relations with the Other" (Martin et al. 2017, pp. 252-253). 
In this chapter, we explore the politics of music teacher reflexivity that emerged during a transnational collaboration, by recognizing both the risks for colonial oppression that are omnipresent in intercultural collaboration on the one hand and, on the other, the potential for the transformation of professional identity through such dialogue. We examine the emerging reflexivity in intercultural dialogue between and among a group of Finnish and Nepali music educators and how the collaboration itself became a complex field of issues of power related to social positions and epistemologies.

\section{Reflexivity and Intercultural Engagement in Late Modernity}

Recent sociological and philosophical literature identifies a number of definitions for reflexivity. The term can be traced to the pragmatist and social constructionist ideas of the self as being "created through social interaction with others as people come to see themselves in the way others see them" (Giddens and Sutton 2014, p. 36). In the social sciences, reflexivity also refers to the "fundamentally reflexive nature of social life per se" (p. 37). Reflexive awareness "is characteristic of all human action... [as] all human beings continuously monitor the circumstances of their activities as a feature of doing what they do" (Giddens 1991, p. 35). As a concept, reflexivity is also used in understanding contemporary late modern society as a " de-traditionalized' social context in which individuals are cut adrift from the social structure and, hence, forced to be continuously reflexive in relation to their own lives and identities" (p. 37). In this emerging post-traditional globalizing society, the balance between tradition and modernity is altered (Giddens 1994), and "modernity is best understood as a matter of the routine contemplation of counterfactuals, rather than simply implying a switch from an 'orientation to the past', characteristic of traditional cultures, toward an 'orientation to the future"" (Giddens 1991, p. 28-29).

Lately, it has been suggested that in the late modern view human beings have the temporal priority, relative autonomy of experience, and causal efficacy that allows them to become social beings with powers of transformative reflection and action, which they can then bring to their social context (Archer 2012). This social relationality is "the fuel or food for the reflexivity" (Donati 2006, p. 39). Donati (2010) points out that "social networks are not only a context where personal reflexivity takes place but can have their own reflexivity of a distinctive kind in respect to personal (agential) reflexivity" (p. 147). Also, situations where joint activities are planned and based on co-production or peer-to-peer production, such as in this inquiry's intercultural dialogue, require more than personal reflexivity, as the consequences pertain to the whole social unit or system. For Donati (2010), such personal and social meta-reflexivity: 
is that form of turning back on oneself by a subject who considers (internally as well as in interaction with others) the outcomes of his/her own deeds, both direct and indirect, and tries to relate them to a horizon of values that transcends what is already given. (p. 159)

Meta-reflexivity, in this sense, is related to such values that might "constitute a utopian life-project" (p. 159) or a utopian social project. This kind of metareflexivity can be seen as part of the intercultural dialogue examined in this chapter. Moreover, such meta-reflexivity involves epistemic reflexivity, albeit not leading to a unified epistemic community, as perspectives and histories vary vastly in the intercultural dialogue in question. It has been argued that in epistemic reflexivity "reflection becomes reflexivity when informed and intentional internal dialogue leads to changes in educational practices, expectations, and beliefs" and "to action for transformative practices" promoting "deep professional learning" (Feucht et al. 2017, p. 234). Besides a commitment to a degree of discomfort, this kind of epistemic reflexivity can be a collective and collaborative activity (Leitch and Day 2000), as in this inquiry.

\section{The Context}

In this inquiry, music teacher reflexivity is explored in the context of an intercultural collaboration between two institutions, the Nepal Music Center (NMC) and the Sibelius Academy, University of the Arts, Helsinki, ${ }^{1}$ that agreed to co-develop an intercultural music teacher education system between Nepal and Finland. ${ }^{2}$ The collaboration between NMC and the Sibelius Academy commenced in 2013, aiming at - in addition to mutual professional learning - the co-creation of a music teacher education program for advanced level students at NMC. In this collaboration, the idea of co-development is not understood as something that is directed, pre-planned, or even necessarily fully orchestrated but rather "a complex process of transformation that comes with difficult choices" and that "must attend to a multiplicity of interests and identities" (Heller and Rao 2015, p. 5). Therefore, the process, rather than the ends, of the development is also a focus of this inquiry.

To support the program's development and to alleviate the lack of opportunities for formal education in the country, the Sibelius Academy provided the opportunity

\footnotetext{
${ }^{1}$ The Nepal Music Center is an institution hosting approximately 300 students and 30 staff members, providing tuition in (Western) popular music, Eastern classical and Nepali folk music, as well as traditional Nepali dance. The Uniarts Helsinki's Sibelius Academy is one of the largest music academies in Europe. At the Sibelius Academy, music teacher education is an extended and integrated 5-year program leading to a Bachelor's and Master's degree.

${ }^{2}$ The collaboration commenced through a project called "Developing music teacher education in Nepal" 2013-2014, funded by the Ministry of Foreign Affairs in Finland, and continued under a larger research project "Global Visions Through Mobilizing Networks: Co-Developing Intercultural Music Teacher Education in Finland, Israel and Nepal," funded by the Academy of Finland in 2015-2020.
} 
for four of the NMC teachers to take part in the Teacher's Pedagogical Studies that are required for teacher competence in Finland. ${ }^{3}$ These pedagogical studies had to follow the general goals of Finnish teacher education that aim at preparing studentteachers for a reflective practice and research-based professionalism, paying particular attention to building "pedagogical thinking skills, enabling teachers to judge the bases and values of one's teaching, and to manage instructional processes in accord with contemporary educational knowledge and practice" (Sahlberg 2015, p. 109). ${ }^{4}$

The pedagogical studies of the NMC teachers included regular assignments, such as writing portfolios, reflective essays, and a final paper based on individually conducted research. The studies were in this case integrated into the curriculum writing for NMC, reading educational and Asian anthropological theories, and philosophical literature far beyond that of the Finnish context. The studies also included a long cycle of group discussions that functioned as the core arena for both for the studies and professional development. Some of the reflective material produced during the pedagogical studies also functioned later as empirical material for this inquiry. In this tailor-made program, for example, presenting one's own research results at international music education conferences became a centerpiece, with the idea that such a wider positioning would trigger critical thinking beyond that of the Finnish-Nepali dialogue, aiming in this way to balance the international impact. Hence, the studies engaged all participants in constant reflection as the main approach, resulting in a hybrid generative process - "grafting" (Ahenakew 2016) where certain ways of understanding knowledge production were applied and also introduced into the Nepali context. In this way, the ideal of reflexive practice in studies and research created an epistemological dominance in this context and the same time also created a distinction between "better" and "worse" ways of developing music education.

\section{Research Approach}

\subsection{Empirical Material and Research Objectives}

The empirical material was generated within the pedagogical studies and intercultural dialogue, as well as through our experiences during and after the process. ${ }^{5}$ The material used for this chapter consists of eight reflective essays that the four NMC teachers wrote as part of their pedagogical studies; five discussions

\footnotetext{
${ }^{3}$ As stipulated in Decree No. $986 / 1998$

${ }^{4}$ The first and third authors of this chapter were responsible for various study modules, and all three authors were involved in the organization and teaching of the studies.

${ }^{5}$ Every participating teacher has signed a consent form that states where the material will be used and by whom. All publications related to the process will be read and accepted by all participants before submission, and the participants have been given the possibility to withdraw from the research at any time.
} 
among the NMC teachers and Finnish teacher-researchers, as well as the first author's research journal; and the collective discussions among the authors. When reflecting on the process of the pedagogical studies as a whole and the intercultural collaborative setting with its inherent power structures, we have engaged with the empirical material through the question: What kind of meta-reflexivity is emerging in the transnational and intercultural dialogues, and in the music educators' professional learning processes, that took place between these two educational institutions?

\subsection{Approach to Analysis}

In addressing the research question, we first analyzed the empirical material and then contested it with our own dominant position in the intercultural dialogical setting. In the analysis, conducted through the NMC teachers' essays and the first author's researcher diary, we explored the taken-for-granted expectation of reflection as a teacher and how this expectation reinforced the distinction between 'us' and 'them' in the intercultural dialogue (Sect. 1). We then moved on to analyze how the professional meta-reflexivity of the participants critically engaged with each of their larger sociocultural frames (Sect. 2). The analysis then proceeded from the first-stage content analysis to the second stage of exploration, in which the outcome of the first-stage analysis was contested through co-reflexive discussions against the scholarship on intercultural interaction and decolonial frames (Sect. 3). In this way, the entire process of participating in the pedagogical studies was reflected against the larger context of power issues, promoting collaboratively produced epistemic reflexivity and co-developed "deep professional learning" (Feucht et al. 2017, p. 234) during the analysis and writing process of this inquiry.

As reflexivity can also refer to simply becoming more aware of one's own biases and theoretical assumptions as qualitative researchers (Giddens and Sutton 2014), in this inquiry we lean on the type of reflexive understanding in which critical, interpretive work "conceptualizes social reality as being constructed, rather than discovered" (Alvesson et al. 2008, p. 480). The second stage of analysis is seen to hold implications for the interpretation of the representation of participant voices (Carducci et al. 2013, p. 15) and also our own self-reflexivity and positionality as scholars toward investigating "the absences, blind spots, and invisibilities inherent in research designed to interrogate, disrupt, and ultimately upend educational inequities" (p. 6). Moreover, we highlight the position that there is no gap between the researcher and research subject (Giddens and Sutton 2014) by including ourselves in the analysis. In this way, instead of aiming only for the endpoints of clarity and explanations, we aim at digging into the complexity, ambiguity, and even paradoxes of the process of intercultural interaction in transnational settings. In what follows, the analysis will be accompanied by direct quotes from the written essays, 
discussions, and researcher journal. ${ }^{6}$ Our own experiences and the power hierarchies in the transnational setting are taken as the backdrop of the overall interpretation and discussion.

\section{Findings}

\subsection{The Journey from Reflection to Reflexivity}

The NMC teachers' professional work consisted not only of teaching in the music school but also of playing music in various bands and studios and performing in public arenas. None of them had a degree in music education but had become teachers through an apprentice model of teaching and learning. Critical (co)reflection as a part of teaching and learning was somewhat unfamiliar to the NMC teachers. Thus, at the beginning of their pedagogical studies, reflection in itself became a central topic of discussion and a focus of collaborative reflexive processes. Instead of reflecting on how to teach music in a more effective way, the following questions emerged: What is reflection? How can you learn to reflect and use it for your work and teacher development? Why are we expected to reflect as teachers?

Reflective assignments became a part of their pedagogical studies, as required for the formal degree. However, after some months, in their written essays, the teachers expressed how understanding the meaning of reflection and learning to articulate one's own thoughts through writing had taken time:

Writing has been very challenging for me. This is not what I have been used to do. Therefore, it took a lot of time to write down my thoughts in words. (Reflective essay, August 2016, teacher 1)

The teachers also recognized the difficulty of establishing a co-reflexive practice. Not only was writing and reading about one's own activities as a teacher a new experience but also sharing ideas with colleagues as a facilitated practice:

At the beginning of this process, there were few awkward moments for me, such as team building activities where you had to open up in a new environment and present yourself as a strong individual, willing to contribute in a team. For me, it took quite a bit of time to understand the whole process, and develop communicative and supportive skills within a group of people. However, things started kicking off as I led myself to share my inner thoughts with others and visualized the connection between all these activities with my performance as a teacher. (Reflective essay, August 2016, teacher 1)

Through the development of a co-reflexive practice, the understanding of the benefits of reflection started to emerge. This was articulated already in the very first written tasks. As one of the teachers wrote in his essay:

\footnotetext{
${ }^{6}$ The quotes have been edited to be more grammatically correct.
} 
This process of working together [in a group consisting of Finnish and Nepali teachers] made me realize that reflecting while working simultaneously is not only possible but very essential to any work that you are doing. (Reflective essay, August 2016, teacher 2).

As reflection was related to interaction with the Finnish partners, it naturally also concerned the assumed differences between the practices in the two countries. Cultural differences were seen as legitimizing the differences between "us" and "them":

In my experience, the working cultures in Finland and in Nepal differ from each other quite a bit. In Finland, work is very precisely planned, everyone knows their exact role in their work and the exact time for the work. The Finns are making a constant reflection on the work, asking questions like why, how, what if, what, paving a path towards deep thinking, that even provokes their own thoughts. (Reflective essay, August 2016, teacher 2).

At the same time, the constant comparison between "us" and "them" helped in identifying one's own professional epistemology, as the time spent with reflective tasks in the studies invited the teachers to ask: Why am I doing my work in the ways I am? For the first author, the process led at times to fundamental questions, such as:

I don't know how to proceed. Educational values? Musical values? What is my take on traditional music? What is important [for me] as an educator, and why? What is important [for me] as a musician, and why? (Researcher diary, 15.2.2016).

The unexpected uncertainty of one's own professional taken-for-granted values and principles questioned the constant comparing and thinking of the differences between 'us' and 'them', and gradually led to realizing that reflexivity in transnational collaboration and intercultural dialogue might move all of us into a deeper consideration of inescapably inherent sociocultural matters.

\subsection{Reflexivity beyond the Existing Practices and Sociocultural Hierarchies: Emerging Meta-Reflexivity Supporting Professional Learning}

The collaborative work on creating a new educational program as part of the studies guided discussions on how to create consistent learning paths for the students, in order to achieve desired educational outcomes:

The overall process of curriculum writing helped me pinpoint the actions that I take in my classes on a deeper level. I started to ask questions: Why do I do things in the way I do? What is the purpose of my actions? What are the outcomes that I am looking for in a student? Am I succeeding in achieving the desired goals? If yes, why? If not, why?" (Reflective essay, January 2016, teacher 2).

Working and co-reflecting as a team inspired further discussions about community building, not just about the teacher community but the whole institutional community, to which the students also belong: 
Moving forward another step has meant becoming self-aware and creating awareness in a team. It has helped us in understanding the broader meaning of music education. It has become a way to explore different dimensions of my teaching and classroom activities. Meanwhile, in the process, I've realized that music education is more than just transferring knowledge; rather, it is about building a strong teacher-student relationship as well as understanding the needs and interests of the students. (Reflective essay, August 2016, teacher 1).

Joint discussions demanded time for building trust, which enabled alternative thoughts to be discussed and tested collegially. One of these complex sociocultural issues was the country's caste system. The caste system has been legally forbidden since 1962 but continues to be a strong force in defining social roles and relations within institutions (Bennett 2008), including educational systems. The caste system thus intersects musical practices and music education in various ways, including the historical perspective that music teachers in Nepal, as also musicians, traditionally come from the lower castes. In their essays, the teachers reflect on how the caste system and cultural habits support ways of conducting mundane activities that do not allow critical thinking or social change and how the possibility of social mobility and thereby individual choice is more relevant for lower caste children and more challenging for upper class children:

In Nepal, ...one's upbringing depends on what caste and what customs one is brought up with. I personally have found it easier to teach pupils who are from the lower middle, or middleclass families, since in the higher classes, children [are] brought up in a strictly disciplined way. [In the higher classes], superstition is also in practice. [For example], you cannot drink water from a glass touched by a lower caste person. These kinds of beliefs and practices often make pupils insecure, low self-esteem, sealed and hesitant beings, as everything in their upbringing is pre-planned. These children have a very slim chance to make decisions. When a teacher comes to know that a pupil comes from such a background, the teacher should try to make the learning and teaching environment as relaxed, friendly, fun, and enjoyable as possible. This type of friendly environment helps the students in opening up and gaining self-confidence. (Reflective essay, January 2016, teacher 2).

In the process of co-reflection among the teachers, the emerging meta-reflexivity that relates to values and being aware of social relationality elicited a social environment wherein teachers' choices, also regarding alternative strategies, started to emerge:

But have we, as teachers, provided the students with such a [supportive and friendly] environment, the right atmosphere in our classes? Have we encouraged the students to make mistakes, not to be afraid of failures, but to take them as a part of their learning process? I presume that asking these questions of ourselves as teachers will definitely increase the self-realization in the teaching sessions. This is very important, as I strongly believe that the teacher's role in making a better society is larger than we have realized. (Reflective essay, January 2016, teacher 2).

The teachers' essays also dealt with the identified professional and economical differences between the two contexts, Finland and Nepal, and how the conditions of professional work shape the reflexive practice, or condone the lack of it:

(07:14) R: Mostly. . .because of the situation in our country ... one job is not enough. So, you are always thinking of getting another job. So, ... we don't reflect on what we have 
done, how we did it. Before, ... I never reflected on my own work, and I haven't seen that being done, either in any company or by our friends. [Here in Nepal] it's always about the new thing: What do we want to do next? And, that's what I grew up with. And, it [the reflective approach] was never part of my working habit. (Discussion 25.3.2016, teacher 4)

Here, reflexivity appears as a privileged activity for those who can afford it. As Indian-born anthropologist Arjun Appadurai (2013, p. 180) argues, "the better off you are (in terms of power, dignity, and material resources), the more likely you are to be conscious of the links between the more and less immediate objects of aspiration." Realizing this led us, the Finnish participants, to turn back to ourselves and ask: Who is reflexivity for? Is reflexivity really a luxury only for those who have the time and means for it?

\subsection{Meta-Reflexivity on Epistemic Imperialism and Exploitation}

NMC's first expectation had been that the Finnish music teacher educators would consult with them and share their knowledge of music teacher education and in this way help in building a new music teacher education program in Nepal. Yet, as shown above, we ourselves were painfully aware that many of our teaching and learning practices, as well as organizational ideas, were challenging the local understanding of who gets to decide what is done, how things are done, when, and by whom. Hence, organizational efficiency rather than the questions of how to teach music became central in the dialogue. As a consequence, we constantly revisited our own understandings, while becoming increasingly aware of the potential consequences of our intervening actions in NMC. The persistent question arose as to how to recognize the colonial frame omnipresent in the dialogue; or rather, how to deal with the fact that the power issues were present throughout. As Leigh Patel (2016) argues:

the location of some actions as within and others outside of systemic coloniality mutes and collapses necessary conversations, not only about the function and impact of oppressive deeds and acts but also about the theories of change for more desired dynamics. (p. 2).

For us, setting up processes of complex reflexivity, instead of introducing professional certainty, became one necessary strategy in our attempts to work through the paradoxes and ambiguity of the situation (see also, Carducci et al. 2013, p. 8).

The NMC teachers' participation in the pedagogical studies repositioned all participants and can be seen as strengthening the already existing hierarchies between the partners. The power hierarchies (established due to professional authority and economical privilege) became even more complex when the initial positions between the Sibelius Academy and the NMC teachers were formally changed from an international teacher exchange relationship to teacher-student relationships, at the same time as the studies provided the NMC teachers access to formal qualifications and professional knowledge. Moreover, the pedagogical studies as a kind of 
'institutional intervention' became a significant part of the research project as a whole, ${ }^{7}$ thus making the position of the NMC teachers even more vulnerable. Therefore, during the studies and the concurrent discussions, the question of what might be epistemic injustice became central. While the studies were conducted with the understanding that practicing reflexivity is a necessity for teachers, the project with its many sub-studies - constantly dealt with such questions as whose knowledge is legitimate in terms of educational organization, when to intervene and when not, and how to anticipate whether our presence and interventions initiated a transformative change or not, as the consequences could only be seen afterward. Indeed, we had to ask: Does enhanced reflexivity itself create tensions that can be more destructive than transformative? Questioning our own actions became an inherent and constantly present part of the process and continues to be so as we write. Hence, the pedagogical studies aimed to support in every way the attempts of the NMC teachers to become equal members of the international community of music educators and researchers. This resulted, for instance, in the NMC teachers becoming co-authors in international peer-reviewed publications, participating as presenters in major international conferences, and their home institution organizing major conferences in Nepal. The joint processes of inquiry in various sub-studies can be seen as having partially blurred the student-teacher division.

Intercultural/transnational collaboration, in which all participants were regarded as learners of some sort, albeit learning different things, can be seen as a strategy to work through the paradoxes encountered. Our own stance in facilitating the collaboration was drawn in large part from Appadurai's understanding, where research can be seen as a democratic activity: "one which is not restricted to the sphere of high science, policy experts, or other elites" (Appadurai 2013, p. 267). Appadurai (2013) eminently advocates that this kind of right for research, meaning to practice epistemological and intellectual capacity to navigate between alternative knowledge horizons, should be included as a basic human right for all, and would be especially relevant to citizens in poorer countries. Accordingly, it became important to consider all participants as equal professionals, working in a joint co-reflexive collaborative process of knowledge production, to support and value all participants' involvement in the inquiry.

Despite these attempts, however, we still had to consider whether facilitating the participants becoming researchers and members of the international academic community was simply an enforced idea, as it seemed unrealistic at least in the beginning for those without any academic background in music education. Moreover, the goals of the pedagogical studies may continue to be seen as epistemic imperialism, which privileges science and research-based knowledge production - a paradox that cannot be hidden in this case and that pertains to the whole of academia, also including the international music education network. As Gorski (2008) points out, there cannot be neutrality, as "in fact the very act of claiming neutrality is, in and of itself, political,

\footnotetext{
${ }^{7}$ Global Visions Through Mobilizing Networks: Co-Developing Intercultural Music Teacher Education in Finland, Israel, and Nepal.
} 
on the side of the status quo" (p. 523). Most importantly, the pedagogical studies that produced the empirical material for the research can themselves be critically seen through the concept of epistemic exploitation, where "epistemic labor is coercively extracted from epistemic agents in the service of others" (Pohlhaus Jr. 2017, p. 22), even though the intentions were for developing "critical consciousness and against marginalization"(Gorski 2008, p. 523). These questions remain to be reflected upon even though when the inquiry as a whole was based on an intention to co-create a hybrid epistemic community that is neither 'Finnish' nor 'Nepali' but an outcome of a community that engages in the creation of Utopian life-projects for all participants.

\section{Conclusion}

This chapter has aimed to show that intercultural dialogue in a transnational project can develop a type of meta-reflexivity that questions one's existential groundings independently of the position of the participant. In such a dialogue, negotiating one's premises, stance, and the ethical relations with the Other - when also confronting and facing a different social order and belief system, among other things - invites or even requires reflection on one's existential groundings. Such reflexivity is an invitation to discomfort, but at the same time, it is an invitation to deep professional learning. The inquiry has illustrated, however, that professional learning in intercultural dialogue is prone to persistent paradoxes that cannot be swiped away, or even solved, but rather will continue haunting in future interactions. Another important question remains: Can or should one expect such commitment to produce discomfort for anyone else except oneself? Although failures have been argued to be a necessary element of intercultural dialogue and learning (Dervin and Gross 2016), the ethical imperative is that failures cannot be welcomed at the cost of harming others. This question relates to the very politics of reflexivity in music education practice and research. Although intercultural dialogue is based on intense communication and serious attempts to form a joint arena for collaboration through discussion, as has been the case for this inquiry, in such a dialogue one can only begin to understand what is not communicated in professional communities, where the personal is often subsumed under the benefits of the organization, project, or the very community, including the research community. The politics of reflexivity thus keeps the questions open, with no final answers and or ultimate solutions.

\section{References}

Ahenakew, C. (2016). Grafting indigenous ways of knowing onto non-indigenous ways of being The (underestimated) challenges of a decolonial imagination. International Review of Qualitative Research, 9(3), 323-340. https://doi.org/10.1525/irqr.2016.9.3.323. 
Alvesson, M., Hardy, C., \& Harley, B. (2008). Reflecting on reflexivity: Reflexive textual practices in organization and management theory. Journal of Management Studies, 45(3), 480-501.

Appadurai, A. (2013). The future as cultural fact. LondonlNew York: Verso.

Archer, M. S. (2012). The reflexive imperative in late modernity. Cambridge: Cambridge University Press.

Bennett, L. (2008). Policy reform and culture change: Contesting gender, caste, and ethnic exclusion in Nepal. In A. A. Dani \& A. de Haan (Eds.), Inclusive states. Social policy and structural inequalities (pp. 197-224). Washington, DC: World Bank.

Biddle, I., \& Knights, V. (2007). Introduction. In I. Biddle \& V. Knights (Eds.), Music, national identity and the politics of location (pp. 1-15). LondonlNew York: Routledge.

Bolton, G. (2010). Reflective practice: Writing and professional development. Los Angeles: Sage.

Carducci, R., Pasque, P. A., Kuntz, A. M., \& Contreras-McGavin, M. (2013). Disrupting façades of clarity in the teaching and learning of qualitative research. Qualitative Research in Education, 2(1), 1-26. https://doi.org/10.4471/qre.2013.01.

Cochran-Smith, M., \& Lytle, S. L. (1999). Relationships of knowledge and practice: Teacher learning in communities. Review of Research in Education, 24(1), 249-305.

Dervin, F., \& Gross, Z. (2016). Intercultural competence in education. Alternative approaches for different times. London: Palgrave Macmillan.

Dervin, F., \& Machart, R. (2015). Introduction: Omnipresent culture, omnipotent cultures. In F. Dervin \& R. Machart (Eds.), Cultural essentialism in intercultural relations (pp. 1-11). Houndmills: Palgrave Macmillan.

Donati, P. (2006). Understanding the human person from the standpoint of the relational sociology. Memorandum, 11, 35-42. http://www.fafich.ufmg.br/ memorandum/a11/donati01.htm. Accessed 10 April 2019.

Donati, P. (2010). Reflexivity after modernity. From the viewpoint of relational sociology. In M. S. Archer (Ed.), Conversations about reflexivity (pp. 144-164). LondonlNew York: Routledge.

Elliott, D. (1995). Music matters: A philosophy of music education. New YorklOxford: Oxford University Press.

Feucht, F. C., Brownlee, J. L., \& Schraw, G. (2017). Moving beyond reflection: Reflexivity and epistemic cognition in teaching and teacher education. Educational Psychologist, 52(4), 234-241.

Giddens, A. (1991). Modernity and self-identity. Self and society in the late modern age. Cambridge: Polity.

Giddens, A. (1994). Living in a post-traditional society. In U. Beck, A. Giddens, \& S. Lash (Eds.), Reflexive modernization: Politics, tradition and aesthetics in the modern social order (pp. 56-109). Cambridge: Polity.

Giddens, A., \& Sutton, P. W. (2014). Essential concepts in sociology. Cambridge: Polity.

Gorski, P. C. (2008). Good intentions are not enough: A decolonizing intercultural education. Intercultural Education, 19(6), 515-525.

Heller, P., \& Rao, V. (2015). Deliberation and development: Rethinking the role of voice and collective action in unequal societies. Equity and development. Washington, DC: World Bank.

Leitch, R., \& Day, C. (2000). Action research and reflective practice. Towards a holistic view. Educational Action Research, 8(1), 179-193.

Martin, F., Pirbhai-Illich, F., \& Pete, S. (2017). Beyond culturally responsive pedagogy: Decolonizing teacher education. In F. Pirbhai-Illich, S. Pete, \& F. Martin (Eds.), Culturally responsive pedagogy: Working towards decolonization, indigeneity and interculturalism (pp. 235-256). Cham: Palgrave Macmillan.

Mateiro, T., \& Westvall, M. (2016). The cultural dimensions of music teachers' professional knowledge. In E. Georgii-Hemming, P. Burnard, \& S.-E. Holgersen (Eds.), Professional knowledge in music teacher education (pp. 157-172). LondonlNew York: Routledge.

Nasar, M., Modood, T., \& Zapata-Barrero, R. (2016). A plural century: Situating interculturalism and multiculturalism. In N. Meer, T. Modood, \& R. Zapata-Barrero (Eds.), Multiculturalism and interculturalism (pp. 1-26). Edinburgh: Edinburgh University Press. 
Patel, L. (2016). Decolonizing educational research. From ownership to answerability. New York London: Routledge.

Pohlhaus, G., Jr. (2017). Varieties of epistemic injustice. In I. J. Kidd, J. Medina, \& G. Pohlhaus Jr. (Eds.), The Routledge handbook of epistemic injustice (pp. 13-26). LondonlNew York: Routledge.

Sahlberg, P. (2015). Finnish lessons 2.0. What can the world learn from educational change in Finland. New YorklLondon: Teachers College.

Schön, D. (1983). The reflective practitioner. How professionals think in action. New York: Basic Books.

Westerlund, H., Partti, H., \& Karlsen, S. (2015). Teaching as improvisational experience: Student music teachers' reflections on learning during an intercultural project. Research Studies in Music Education, 37(1), 55-75.

Vilma Timonen is a Lecturer in Folk Music at Sibelius Academy, University of the Arts Helsinki. Her extensive career as a folk music educator and musician comprehends working in various fields of teacher education as well as being one of the pioneers bringing traditional Finnish folk instrument kantele into new musical environments. As a researcher, her work focuses on intercultural collaborations as means for educational development.

Marja-Leena Juntunen ( $\mathrm{PhD}, \mathrm{MM})$ works as professor of Music Education at the Sibelius Academy, University of the Arts Helsinki, Finland. She has published widely in international research journals and is a contributor to anthologies such as Approaches to Teaching General Music: Methods, Issues, and Viewpoints. She has served as a review reader in several research journals. She is a researcher and group leader in the current ArtsEqual research initiative.

Heidi Westerlund is a professor at the Sibelius Academy, University of the Arts Helsinki, Finland, where she is also responsible for the music education doctoral studies. She has published widely in international journals and books. Her research interests include higher arts education, music teacher education and professionalism in the arts, collaborative learning, cultural diversity, and democracy in music education.

Open Access This chapter is licensed under the terms of the Creative Commons Attribution 4.0 International License (http://creativecommons.org/licenses/by/4.0/), which permits use, sharing, adaptation, distribution and reproduction in any medium or format, as long as you give appropriate credit to the original author(s) and the source, provide a link to the Creative Commons license and indicate if changes were made.

The images or other third party material in this chapter are included in the chapter's Creative Commons license, unless indicated otherwise in a credit line to the material. If material is not included in the chapter's Creative Commons license and your intended use is not permitted by statutory regulation or exceeds the permitted use, you will need to obtain permission directly from the copyright holder.

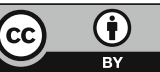

